\title{
Splenic Rupture Related to Birth
}

National Cancer Institute

\section{Source}

National Cancer Institute. Splenic Rupture Related to Birth. NCI Thesaurus. Code

C116839.

Disruption of the spleen incurred during delivery. 